\title{
A nova disciplina de sistemas econômicos comparados: uma proposta
}

\author{
RICARDO LUIS CHAVES FEIJÓ*
}

The new discipline of comparative economic systems: a proposition. This article offers elements for a reorientation of the subject matter of the discipline "Comparative Economic Systems" with the impact of the fall of the Berlin's wall. Thus, we argue that in the context of the modern democratic society the political choice between society models occurs in a narrower set of options. Thus the study of pure forms of socialism is of historical interest, but he is not relevant to this discipline since it must prioritize the debate around the choice of compatible alternative models within the rule of law. So the article offers a new program for this discipline, able to describe and to understand the diversity of systems between countries that had opted for mixing market economy.

Key-words: Comparative Economic Systems; Socialism; Liberalism; Democracy. JEL Classification: P51.

\section{INTRODUÇÃO}

A disciplina Sistemas Econômicos Comparados (SEC) praticamente desapareceu dos currículos escolares do curso de graduação de Economia em função da queda do muro de Berlim, há dezesseis anos, que tornou obsoletos os modelos de controle centralizado da economia, com completo planejamento estatal e coletivização dos meios de produção. No entanto, argumenta-se no presente artigo que os estudos em SEC podem ser resgatados desde que sejam feitas importantes inovações na ementa da disciplina.

O artigo propõe a identificação de um conjunto de sistemas econômicos mais descritivo do que vem ocorrendo em nossos dias. Não apenas os sistemas de países desenvolvidos e democráticos, mas também as alternativas que vêm sendo

\footnotetext{
* Professor Associado da Faculdade de Economia e Administração de Ribeirão Preto da Universidade de São Paulo. E-mail: riccfeij@usp.br. Submetido: Março 2005; aceito: Outubro 2006.
} 
testadas alhures em países que saíram da centralização econômica comunista e estão procurando formas capitalistas e mistas de organizar suas economias, como nos casos de Rússia e China, bem como se pensando também em diversos modelos que têm sido tentativamente adotados por países em desenvolvimento. Não está se propondo o abandono da preocupação com o estudo de princípios gerais de estruturação de sistemas econômicos. Pelo contrário, a próxima seção explora as bases intelectuais, os valores filosóficos e a visão de sociedade dos sistemas econômicos tradicionais, considerando todo o espectro possível. Também se analisa nesta seção as ideologias subjacentes a diferentes opções políticas indo da extrema esquerda comunista, passando pelo centro liberal, até a extrema direita fascista. Os princípios gerais que norteiam sistemas econômicos serão associados a cada uma das ideologias analisadas. Considera-se que apenas pela identificação destes princípios pode-se analisar a realidade concreta e, sobretudo, a prática política de atores e partidos políticos em diferentes países.

Feito isso, a fim de desenvolver a proposta de uma nova disciplina de SEC, o artigo divide-se em mais três seções. A seção seguinte argumenta em prol da atualização da disciplina de modo a adequá-la à presente realidade política multifacetada. Considerando-se que certas ideologias como o fascismo, o comunismo e o conservantismo monárquico praticamente deixaram de influenciar sistemas econômicos concretos, excetuando-se alguns casos isolados de países remanescentes e de pouca importância no cenário mundial, esta seção sugere que a nova SEC concentre-se em modelos com potencial de enquadrar um maior número de casos concretos, deixando a preocupação tradicional com modelos "puros”, que no máximo, e com sérias reservas, se aplicariam a uns poucos casos pitorescos de países recalcitrantes. Não se está afirmando que os sistemas puros e seus princípios deixaram de existir enquanto sistemas de crenças ideológicas, ou que deixaram de influir nas propostas e práticas políticas de grupos e partidos políticos.

A terceira parte aponta para a inadequação de contrastar-se sistemas econômicos "puros" dentro da dicotomia esquerda-direita. Argumenta-se que mais importante, hoje em dia, é o estudo de sistemas econômicos com crenças filosóficas e sociais distintas e que impliquem variados graus de intervenção do estado na economia, dentro de um contínuo de modelos ordenados segundo critérios e compatível com sociedades com graus também variados de democracia. O que se estará propondo logo mais é que a SEC deixe de priorizar a comparação entre sistemas "puros" a fim de se concentrar em modelos baseados em situações reais: modelo anglo-saxão, renano, franco-germano, escandinavo, japonês, dos países da América Latina etc. Tal pressuposto será analisado e fundamentado teórica e empiricamente.

Não se pretende fazer uma mera classificação, tendo como eixo a maior ou menor ingerência do Estado na economia. Cada qual dos modelos de sistema econômico associa-se não só a princípios gerais de como a economia deve funcionar, como também a elementos de conformação filosófica situados num ponto específico do espectro ideológico ou uma combinação particular de elementos trazi- 
dos de diferentes pontos do referido espectro. Não se trata de impor uma classificação unidimensional. O que se pretende é construir, da observação de modelos concretos compreensivos, uma seqüência de tipos ordenados segundo critérios extraídos da exposição anterior das ideologias.

A seção final desenvolve, à luz das considerações anteriores, a nova agenda dos temas pertinentes à renovada disciplina de SEC.

\section{REVENDO O ESPECTRO POLÍTICO ESQUERDA-DIREITA}

No século XIX, três principais ideologias políticas disputavam o poder. Duas delas, o liberalismo e o socialismo, eram crias da Revolução Francesa de 1789. Estavam alicerçadas respectivamente nos valores máximos de liberdade e igualdade. A outra ideologia procura se firmar como uma negação das idéias revolucionárias e na defesa da ordem antiga: o conservantismo. A liberdade era valor supremo na ideologia dos liberais clássicos do século XIX. Eles prezavam e defendiam as liberdades civis (os direitos humanos, a liberdade de expressão etc.). Os socialistas também se apegaram ao valor da liberdade, no entanto afirmavam que as liberdades civis dos liberais e a limitação ao poder arbitrário de um estado não assegurariam a liberdade plena enquanto subsistissem as regras do sistema capitalista. A liberdade só viria com o fim da mercadoria e da exploração do mercado; com o fim da alienação capitalista.

Ainda mais surpreendente, também os conservadores do século XIX conheciam e defendiam um conceito de liberdade. Sua concepção de liberdade era idealista, uma idéia de liberdade compatível com os sistemas absolutista e hierárquico. O Estado forte impõe a disciplina que permite às pessoas alcançarem a liberdade do desejo e da tentação materialista. Enquanto a concepção liberal de liberdade é ilustrada pelo exemplo de pisar ou não na grama, a noção idealista de liberdade definia-a simplesmente como o não querer pisar na grama.

Com base nos três valores da Revolução de 1789 (liberdade, igualdade e fraternidade), pode-se situar as diferentes ideologias do século XIX pela maneira como cada qual os define e pelo peso relativo que conferem a cada um deles. A tabela abaixo ilustra esse ponto. Arrisca-se a dizer que o principal valor para os liberais é a liberdade, para os socialistas a igualdade e para os conservadores a fraternidade. Socialistas e conservadores mantém a adesão a um conceito de liberdade que se define aqui como ambíguo, pois são evidentemente muito idiossincráticos, ligados que estão a concepções filosóficos idealistas muito particulares. A igualdade também é defendida pelos liberais, mas apenas a igualdade formal (igualdade perante as leis e igualdade de oportunidade). Considerando um modelo liberal de indivíduos naturalmente desiguais, a igualdade formal produz resultados em que as situações de cada qual tornam-se bastante desiguais. O valor de fraternidade é ambíguo entre liberais e socialistas enquanto os conservadores são mais consistentes em afirmar a hierarquia como condição para a fraternidade. 
Tabela 1: Valores e ideologias

\begin{tabular}{llll}
\hline Ideologia/Valores & Liberdade & lgualdade & Fraternidade \\
\hline Liberais & $\begin{array}{l}\text { Valor alto: } \\
\text { liberdade individual }\end{array}$ & $\begin{array}{l}\text { Valor ambíguo: } \\
\text { igualdade formal }\end{array}$ & $\begin{array}{l}\text { Valor ambíguo: } \\
\text { fraternidade no mercado }\end{array}$ \\
\hline Socialistas & $\begin{array}{l}\text { Valor ambíguo: } \\
\text { libertar-se do capital }\end{array}$ & $\begin{array}{l}\text { Valor alto: } \\
\text { igualdade absoluta }\end{array}$ & $\begin{array}{l}\text { Valor ambíguo: } \\
\text { fraternidade universal }\end{array}$ \\
\hline Conservadores & Valor ambíguo: & Nenhum valor & Valor alto: fraternidade \\
& liberdade interior & & na hierarquia \\
\hline
\end{tabular}

Os socialistas prezam a igualdade ainda mais que a liberdade. Eles não se contentam com a igualdade formal, propugnam pela noção de igualdade econômica que só é alcançada com a socialização ou nacionalização (propriedade do Estado) dos bens que criam riqueza. Os princípios democráticos de igualdade de oportunidade e igualdade perante a lei não são suficientes, pois não podem impedir que o forte explore economicamente o fraco no mercado livre.

O tradicional espectro político esquerda-direita é um importante modelo conceitual que situa as grandes ideologias, que nasceram no século XIX e se consolidaram no século passado, num continuum da esquerda para a direita. À direita estariam as crenças políticas que preconizam a manutenção de um status quo hierárquico, à esquerda os adeptos da reforma liberalizante e igualitária. A diferença essencial entre esquerda e direita reside no grau de adesão ao valor de igualdade. Os extremos do espectro mantêm atitude oposta em relação à noção de igualdade como um ideal social. A esquerda luta pela igualdade absoluta entre todas as pessoas, a direita não vê a igualdade como condição desejável, pelo contrário, ela defende abertamente a desigualdade como algo inevitável e até desejável.

A tabela 2 identifica as ideologias e as posiciona no espectro político esquerda-direita. O socialismo, que foi a terceira grande ideologia do século XIX, tem suas origens na fase radical da Revolução Francesa. Sua característica definidora é a defesa da eliminação da propriedade privada dos meios de produção (incluindo comércio, indústria, finanças, agricultura e recursos naturais) como uma condição para se atingir a igualdade econômica. No século XIX, os partidos socialistas europeus continentais intitulavam-se democrático social. Depois da Revolução Russa de 1917 organiza-se o movimento comunista. Os comunistas são socialistas de linha dura que desprezam a forma democrática de governo. Nessa ideologia, apenas uma estrutura política autoritária e o regime de partido único poderiam impor e defender uma economia socialista. No lado esquerdo do espectro político, residem essas duas modalidades de socialismo: na extrema esquerda o comunismo de inspiração soviética e a seu lado a antiga social-democracia (socialismo) que são duas formas de marxismo adversárias encarniçadas entre si. 
Tabela 2: Espectro político esquerda-direita e as ideologias

\begin{tabular}{|c|c|c|c|c|c|c|}
\hline $\begin{array}{l}\text { extrema } \\
\text { esquerda }\end{array}$ & esquerda & $\begin{array}{l}\text { centro } \\
\text { esquerda }\end{array}$ & centro & $\begin{array}{l}\text { centro } \\
\text { direita }\end{array}$ & direita & $\begin{array}{l}\text { extrema } \\
\text { direita }\end{array}$ \\
\hline comunismo & socialismo & $\begin{array}{l}\text { liberalismo } \\
\text { do estado de } \\
\text { bem-estar social }\end{array}$ & $\begin{array}{l}\text { liberalismo } \\
\text { clássico }\end{array}$ & $\begin{array}{l}\text { liberalismo } \\
\text { conservador }\end{array}$ & $\begin{array}{l}\text { conservantismo } \\
\text { monárquico }\end{array}$ & fascismo \\
\hline
\end{tabular}

Os liberais clássicos estão no centro do espectro ideológico. Defendem a igualdade de oportunidade e igualdade perante a lei, ao mesmo tempo são contra a violação da liberdade individual e da liberdade de opção (a esquerda viola essas liberdades em seu esforço para alcançar a plena igualdade social e econômica). Depois da Segunda Guerra Mundial, os sociais democratas europeus continentais abandonam seu compromisso com o socialismo (propriedade pública dos meios de produção) em favor do liberalismo do estado do bem-estar social. Deslocam-se, portanto, um pouco mais para a direita, ao constatarem ser inviável a meta de socialização dos meios de produção em sociedade democrática. Nos Estados Unidos, a alcunha liberal aplica-se aos defensores do estado de bem-estar social e é convergente com o moderno conceito de social-democracia dos europeus. Trata-se de uma ideologia de centro-esquerda. Na América do Norte, o que se conhece como conservador é simplesmente uma ideologia liberal conservadora. São liberais que se opõem ao estado grande, enquanto os liberais americanos de esquerda defendem o governo grande na construção do estado de bemestar social.

Este tipo de liberalismo conservador, também chamado de neoliberalismo (seguidor das idéias de Hayek e Friedman), não se confunde em hipótese alguma com o conservantismo monárquico do século XIX. Os conservadores liberais querem limitar os poderes sociais do governo e defendem o laissez-faire. Desejam restringir ao máximo o poder do governo. No entanto, aceitam medidas públicas para promover uma igualdade maior através de programas de assistência social e outros meios, desde que tais iniciativas não inchem o tamanho do governo. Os conservadores do século XIX na Europa continental defendiam o estado monárquico forte. Os conservadores de hoje em dia estão mais ao centro do espectro político a favor da liberdade pessoal e de certa igualdade social.

O fascismo, junto com o nazismo (sua variante alemã), representam um movimento da extrema direita em prol da regeneração nacional contra a ameaça do comunismo e da democracia liberal. $\mathrm{O}$ fascismo é de extrema direita não apenas por ser inimigo mortal do comunismo, mas também, e principalmente, pela sua oposição fundamental ao valor da igualdade. $\mathrm{O}$ fascismo não se confunde com o conservantismo do século XIX, embora ambos os movimentos ideológicos abominem a igualdade humana. Há uma ligação histórica entre o fascismo e o conservantismo monárquico, como movimentos da direita. O conservantismo monárquico apega-se a um tipo de elitismo ligado aos antigos valores das famílias 
tradicionais da Europa, o fascismo é um movimento de massas inimigo da igualdade racial entre os povos (tida como fonte de ruína da humanidade) - ver (Stackelberg, 2003).

A característica comum dos extremos opostos do espectro político (comunismo e fascismo) é a de serem movimentos radicais. Os radicais extremistas são autoritários, intolerantes, propensos à fraude e à violência. Não permitem desvio ou oposição ao seu ideal desejado (igualitário ou desigualitário). Desejam impor seu ideal a todos os outros. São capazes de qualquer coisa para alcançá-lo. A extrema esquerda sonha com sua utopia igualitária em que os fracos e os fortes partilham igualmente os benefícios de sua sociedade. Na utopia da direita, os fortes recebem os benefícios que lhe são devidos em virtude de sua superioridade natural, enquanto os fracos são dispensáveis, privados e excluídos. As ideologias não extremistas podem seguir, ou não, o mesmo ideal utópico dos extremistas; no entanto mesmo comungando um ideal não utilizam os mesmos meios. Acreditam poder alcançá-lo por meio da prática democrática.

Repassando agora essas várias ideologias políticas ao longo do espectro esquerda-direita, é importante investigar-se o conjunto de crenças morais, filosóficas e a visão de sociedade que identifica e separa cada uma das diferentes concepções esquerda, direita e centro. A esquerda acredita no ideal de justiça social e na racionalidade humana construtivista. A direita adere ao ideal platônico de justiça em sociedade e na ordem natural (ou divina) da sociedade. O centro liberal desdenha da idéia de justiça social e oferece em troca a noção de regras justas do convívio social. Defende a racionalidade humana limitada e o modelo de ordem social espontânea. A tabela 3 sintetiza e compara as teses principais de cada uma das concepções de sociedade.

Tabela 3: Crenças filosóficas e visão de sociedade de

cada uma das ideologias: esquerda, direita e centro

\begin{tabular}{lcc}
\hline Ideologia & Crenças filosóficas & Visão de sociedade \\
\hline Esquerda & justiça social & construtivista \\
\hline Centro & regras justas & ordem \\
& em sociedade & espontânea \\
\hline Direita & justiça platônica & ordem natural \\
\hline
\end{tabular}

Os socialistas perseguem um ideal de justiça social. Consideram o socialismo um sistema mais justo, pois estende benefícios econômicos iguais a todos os membros da sociedade. Tal noção de justiça social somente se mantém na medida em que a sociedade é pensada como uma organização racional deliberada. É a visão construtivista de sociedade, na qual sua organização é entendida como um ato que aponta a determinados propósitos praticado por um grupo privilegiado de indivíduos.

Os liberais herdam a tradição do Iluminismo escocês, reforçada depois por Carl Menger, que considera o fenômeno social como sendo conseqüência não in- 
tencional da ação humana. A sociedade não é natural, pois é fruto da ação humana, porém não é um artifício deliberado da razão humana, pois se trata de uma ordem espontânea.

A direita tradicional imagina a sociedade como uma ordem natural ou de desígnio divino na qual a hierarquia é tida como benéfica por estar conforme a natureza ou a vontade de Deus. Platão, em sua obra A República, discute o conceito de justiça. Para ele, a justiça em sociedade consiste em deixar com que cada pessoa desempenhe o papel em que ela está apta por condição de nascimento, por suas qualidades naturais. As pessoas nascem muito diferentes entre si, e é justo, argumenta Platão, que essas diferenças sejam respeitadas. Posição oposta ao do igualitarismo que tenta nivelar as pessoas, na crença de que elas sejam naturalmente iguais.

Então esse empolgante debate sobre os pressupostos filosóficos das ideologias explica as diferentes visões de sociedade. Cada qual das ideologias políticas, da extrema esquerda à extrema direita, propugna um sistema econômico. Os comunistas e os socialistas defendem a coletivização dos meios de produção, os primeiros recorrem à ditadura totalitária enquanto os socialistas convivem e se acomodam a uma forma de governo constitucional e representativa. Como conseqüência desta acomodação, os socialistas são menos "coletivizantes" que os comunistas, aceitam a coexistência da propriedade privada e lutam pela propriedade pública nos limites das possibilidades de um estado de direito democrático. Os liberais comprometem-se com a propriedade particular e com a livre atividade econômica.

Dentro do modelo liberal coexistem diferentes modalidades. Os liberais de centro da tabela 2 defendem um governo pequeno, expresso na máxima de John Locke "o melhor governo é aquele que menos governa", porém estão abertos a discutirem os casos particulares em que é desejável a intervenção do governo. Antes de serem dogmáticos, os liberais clássicos discutem os casos em que o principio liberal de não intervenção é mais desejável.

Os liberais conservadores de centro-direita, os neoliberais, são mais contundentes na defesa da não-intervenção do estado na economia, guiados pelos princípios desenvolvidos em autores como Mises, Hayek e Friedman. A adesão ao modelo de sociedade "jogo da catalaxia" parece justificar a não-intervenção em praticamente todos os casos. São adeptos do governo mínimo, de políticas que estimulem o setor privado a cuidar do bem-estar da população em vez de um estado grande provedor de bem-estar social. Os liberais de centro-esquerda (os liberais na acepção norte-americana) defendem o estado de bem-estar social, com programas de assistência social de massa. Muitos deles, especialmente na Europa, são sociais-democratas que na convivência democrática abandonaram o ideal socialista da coletivização e passaram a aderir ao princípio da propriedade privada, com a ressalva de um estado grande na provisão de onerosos programas assistenciais à população.

As ideologias políticas de direita superadas pela história também asseveram sistemas econômicos particulares: o conservantismo monárquico tradicional se- 
gue um receituário mercantilista da associação de um estado forte com grandes grupos que detém para si monopólios de indústria e comércio. $\mathrm{O}$ fascismo, em seus propósitos militaristas, associa-se ao grande capital a fim de alimentar a máquina de guerra e oferecer benesses às massas. A tabela 4 relaciona as ideologias políticas com os princípios gerais que norteiam os sistemas econômicos.

Tabela 4: Relação entre ideologia políticas e princípios gerais que norteiam os sistemas econômicos.

\begin{tabular}{ll}
\hline Ideologia & \multicolumn{1}{c}{ Princípios gerais que noteiam os sistemas econômicos } \\
\hline Comunismo & $\begin{array}{l}\text { Economia centralmente planejada com a coletivização dos meios de } \\
\text { produção. }\end{array}$ \\
\hline Socialismo & $\begin{array}{l}\text { Forte presença do estado na economia, grau acentuado de coletivização } \\
\text { dos meios de produção. Coexistência com a propriedade privada e o } \\
\text { mercado. Compatibilidade com o sistema político democrático. }\end{array}$ \\
\hline Liberalismo do estado & $\begin{array}{l}\text { Sistema de livre-mercado com governo grande. Elevada carga tributária } \\
\text { de bem-estar social }\end{array}$ \\
\hline Liberalismo clássico & $\begin{array}{l}\text { Sistema de livre-mercado com governo pequeno. O estado intervém } \\
\text { sempre que o critério ético assim o desejar. }\end{array}$ \\
\hline Liberalismo & $\begin{array}{l}\text { Sistema de livre-mercado com governo mínimo. Apenas poucas } \\
\text { exceções para a presença do estado. Políticas sociais a cargo do setor } \\
\text { privado com o incentivo do governo. }\end{array}$ \\
\hline Conservador & $\begin{array}{l}\text { Sistema de privilégios de nascimento e de concessões de monopólios } \\
\text { comerciais e industriais. Elevado grau de protecionismo. }\end{array}$ \\
\hline Fascismo & $\begin{array}{l}\text { Economia planejada visando propósitos militares. Associação com o } \\
\text { grande capital. }\end{array}$ \\
\hline
\end{tabular}

Embora não se pretenda aqui detalhar o estudo do sistema econômico em si mesmo, o que se quer evidenciar é a associação estreita entre a ideologia política e o sistema econômico. Este é um aspecto fundamental que será levado em conta na próxima seção que trata de atualizar o espectro político para os estudos de SEC.

\section{ATUALIZANDO O ESPECTRO POLÍTICO PARA ESTUDOS DE SEC}

A adequação do modelo conceitual que situa as grandes ideologias políticas num contínuo da esquerda para a direita tem sido questionada. Hoje em dia, com o fim da esquerda histórica (comunismo e socialismo) e com o fim da direita histórica (conservantismo monárquico e fascismo), o espectro político esboçado na seção anterior parece não mais se aplicar na compreensão da realidade atual, uma vez que é cada vez mais difícil definir com clareza as categorias esquerda e direita. 
Não obstante isso, a distinção esquerda-direita ainda é útil em alguns aspectos, mesmo com o fim das ideologias radicais. Evidentemente ela é importante para o historiador que estuda e procura compreender os objetivos e valores fundamentais dos movimentos políticos dos séculos XIX e XX. Ademais, ela também é importante para economistas, sociólogos, cientista políticos e outros cientistas sociais enquanto um instrumento descritivo e analítico.

Sem diminuir a validade do modelo conceitual esquerda-direita, é inegável que hoje em dia estamos todos mais próximos do centro do espectro em se tratando das variações políticas que existem numa sociedade democrática. As diferenças ideológicas situam-se em algum ponto transitando da centro-esquerda à centro-direita de um espectro político reduzido. $\mathrm{Na}$ esquerda, a ideologia do comunismo deixou de ser uma opção política efetiva com a queda do muro de Berlim. Na direita, há muito tempo o conservantismo monárquico e o fascismo são sistemas relegados ao interesse quase exclusivo do historiador. Mesmo o socialismo, entendido ao pé da letra como a socialização de todos os meios de produção, não parece um ideal compatível com as modernas práticas democráticas. Por "meios de produção" pode-se subentender quase tudo, na indústria o setor de bens de capital, bens intermediários, em suma, tudo o que não seja estritamente bens de consumo. É simplesmente nula a possibilidade de se alcançar esse nível de contestação à propriedade privada em uma sociedade regida por um estado de direito.

Nesse âmbito, o estudo de SEC tem como objeto identificar os sistemas econômicos atuais compatíveis com a moderna prática democrática. São destarte os sistemas que decorrem das concepções ideológicas de um espectro político esquerda-direita atualizado, em que apenas subsistem as três alternativas tradicionalmente de centro: a social-democracia do estado de bem-estar social, o liberalismo clássico e o neoliberalismo. A tabela 5 identifica essas posições do espectro político atualizado.

Tabela 5: Atual espectro político esquerda-direita e as ideologias

\begin{tabular}{lll}
\hline esquerda & centro & direita \\
\hline & & \\
\hline social democracia do & liberalismo & neoliberalismo \\
estado de bem-estar social & & \\
\hline
\end{tabular}

Quais as implicações dessa atualização do espectro político? O que muda em relação às formas tradicionais de estudo comparado de sistemas econômicos? Não se pretende apagar da agenda dos economistas os estudos sobre as formas puras do sistema econômico. Também não se pretende que a SEC se preocupe apenas em classificar os sistemas econômicos em termos ideológicos, situando-os em alguma região do espectro político. A crise da SEC surgiu espontaneamente com a queda do muro de Berlim. Antes disso, muitos acreditavam que as formu- 
lações teóricas do socialismo, quer no modelo do socialismo marxista ou na versão do socialismo de mercado, estavam a disposição dos partidos de plantão para, uma vez alçados ao poder, testarem sua aplicação em cenários específicos. A disciplina comparava as formulações teóricas dos socialistas com as refutações feitas, principalmente, por economistas da escola austríaca como Mises e Hayek. O debate ficava em modelos puros, essencialmente estava reproduzindo para o âmbito da SEC a famosa controvérsia do século XX sobre a possibilidade do cálculo racional no socialismo. A Controvérsia Socialista, ou Debate do Cálculo Socialista, como ficou conhecido, foi um dos mais notáveis episódios da história do pensamento econômico (disciplina HPE), não se nega isso. No entanto, este tema, hoje em dia, é objetivo de discussão da HPE e não da SEC. O ponto central do argumento é este: a SEC foi extraída dos currículos escolares porque não conquistou para si um espaço próprio, não delimitou a sua temática de maneira atrativa, ocupou outras searas intelectuais, sobrepôs-se com outras disciplinas da economia e enfraqueceu-se. A debilidade ficou mais visível com o fim das utopias associado à derrocada do socialismo real.

Sistemas econômicos puros, associados a opções extremadas e anacrônicas do espectro, ainda podem ser incorporadas na ementa da SEC. Mas constituiriam um tópico especifico do curso, algo como "modelos teóricos estilizados", e não o objeto principal do estudo. A reflexão teórica principal desta disciplina deve-se pautar pela tentativa de enquadrar os sistemas econômicos atuais em tipologias bem fundamentadas: a base não é unidimensional, não prioriza apenas o grau de intervenção do Estado, mas procura identificar o estado de crenças associado a cada opção. Fá-lo, mas não de uma maneira excessivamente dispersa e específica. Não se trata de uma mera exposição exaustiva de cada caso, a evidência de formas específicas em certo país, porém, trata-se da tentativa de enquadramento das formas variadas em tipos ideais suscitados pelo trabalho do teórico. Enquanto teoria, a SEC preocupa-se com os elementos comuns de um grupo de experiências; quer apontar que um rol de países eventualmente segue estratégia assemelhada na construção de sistema econômico, alimentada em cada caso por um referencial de crenças e valores aproximadamente compartilhados dentro da classe em que se encontram. Não é um mero esforço classificatório que se encerra em si mesmo, nenhuma tentativa de classificação arbitrária deve ser feita. Apenas com relação aos elementos ideológicos pode-se remeter ao espectro político. O espectro certamente é um tanto idiossincrático. E a classificação das ideologias muda de acordo com o enfoque do analista. Por exemplo, a teoria do totalitarismo coloca comunistas e fascistas na mesma ponta da classificação ao invés de em posições diametralmente opostas.

A classificação política das ideologias, feita nessa seção, representa um razoável consenso entre cientistas políticos. Entretanto, não é universal. Mas não se pode relativizar exageradamente as possibilidades de enquadramento de ideologias a ponto de cada analista poder construir a sua própria classificação. Mesmo com margem de manobra das opções classificatórias, fica o argumento importante de que é preciso vincular o sistema econômico a uma opção político-ideológica 
de fundo, mesmo que de acordo com as inclinações de cada analista a maneira de posicionar estas opções conheça uma ligeira mudança relativa.

\section{A INADEQUAÇÃO DE CONTRASTAR-SE SISTEMAS ECONÔMICOS PUROS PARA O ESTUDO DE SEC}

A primeira questão a ser investigada é o sentido atual do estudo comparativo de sistemas econômicos com as transformações recentes que conheceu o mundo. Até a década de 1980, as metodologias e os enfoques alternativos adotados nesse estudo eram explorados em uma ampla gama de livros-texto. Dentre eles, eram bastante conhecidas as cinco referências: Lindblom (1977), Neuberger e Duffy (1976), Pryor (1985), Vickers e Arrow (1989) e Zimbalist e Sherman (1984). O livro se Lindblom explora a inter-relação de mercados com as ações políticas de grupos organizados. Neuberger procura extrair recomendações para a tomada de decisão econômica com base na comparação sistemática de sistemas econômicos. É um livro recheado de estudos de caso. Pryor prioriza o enfoque histórico e institucional dos sistemas econômicos. Vickers e Arrow centralizam a questão da privatização. A obra de Zimbalist e Sherman também é rica em estudos de caso.

As diferentes metodologias propostas para o estudo de SEC, embora com especificidades, compartilham a estratégia de "compartimentalizar" o estudo em tópicos, nos quais se estuda, num deles, o sistema capitalista e noutro o sistema econômico socialista. E, por fim, uma seção da disciplina dedica-se a estudos de casos, centrados em um grupo seleto de países.

Em cada um dos primeiros dois tópicos de SEC, duas abordagem prevaleciam amplamente:

1. O estudo do sistema econômico "puro", ou seja, do funcionamento teórico de um sistema econômico abstrato apoiado em instituições ideais: o capitalismo ideal do livre-mercado com as instituições que lhe são adequadas e o socialismo teórico.

2. A abordagem de SEC que se dedica ao estudo da evolução e da transformação dos sistemas capitalistas e socialistas.

No primeiro tópico, começa-se com a descrição dos modelos socialistas de inspiração marxistas desenvolvidos teoricamente nos anos 1920 por autores alemães dentre eles Walther Rathenau, Otto Neurath, Otto Bauer, Otto Leichter e Karl Polanyi. ${ }^{1}$ São modelos de sistemas econômicos em que todos os meios de produção são propriedade estatal, não existem moeda, preço e lucro; e a econo-

\footnotetext{
${ }^{1}$ A descrição e a referência desses trabalhos aparece em Chaloupek (1990).
} 
mia é coordenada pelo planejamento central do Estado que é feito em termos de unidades físicas ou o equivalente valor em trabalho.

Outro modelo ideal de socialismo surgiu tempos depois em meados dos anos 1930 quando, com base nos trabalhos de Walras, Cassel e de outros, se propôs, pela primeira vez, a aplicação da teoria microeconômica da época na determinação teórica do funcionamento de uma economia centralmente planejada. A aplicação ortodoxa das teses marxistas dos primeiro modelos de socialismo foi substituída por nova proposta em que se abandona o marxismo em troca da adoção de modelos ditos "socialistas de mercado" que se apóiam no uso da técnica do equilíbrio geral algébrico entre todos os mercados de uma economia. A inspiração desta linha teórica vem do trabalho pouco anterior do economista italiano Enrico Barone que em 1908 publicou numa revista econômica de seu país o ensaio "O Ministério da Produção no Estado Coletivista" (Barone, s.d).

Nos anos 1930 e 1940, autores como Oskar Lange (1936), Abba P. Lerner (1944) e A. Bergson (1948) desenvolvem o referido modelo de socialismo adicionando-lhe a hipótese de que o comitê central de planejamento, longe de substituir o mecanismo de formação de preços dos mercados, utiliza os mercados como um dispositivo auxiliar na busca dos preços de equilíbrio da economia (uma tarefa difícil num modelo puro de equilíbrio geral). O chamado modelo socialista de mercado substitui a solução teórica das equações do equilíbrio geral por uma solução por tentativa e erro deixando os mercados operarem. Essencialmente, o modelo limita o grau de competição dos mercados substituindo-a, em parte, pela adoção de regras de determinação de escala de produção e de formação de preços estabelecidas pelo planejador central. Ajustam-se os preços e quantidades de forma a aproximar a economia real do equilíbrio teórico.

Tanto o socialismo marxista quanto o socialismo de mercado representam tão-somente construções teóricas. Destarte, eles descrevem um sistema econômico puro. Não descrevem as condições específicas em que seriam aplicados: quais as instituições e o ethos social que permitiriam viabilizá-los? Qual a estrutura legal e burocrática para a sua implementação? Qual o grau de desenvolvimento econômico requerido para a sua aplicação? Estas e outras questões que dizem respeito à aplicação dos modelos não são tratadas em casos específicos. No sentido de torná-los aplicáveis, novas versões de equilíbrio geral para economias socialistas foram propostas por H. Zassenhaus (1956), A. Bilimovich e W. Krelle, mas nunca realmente aplicadas. ${ }^{2}$ Nos anos 1970, Kantorovich (1965) tentou, sem sucesso, implementar esses modelos na Rússia soviética. ${ }^{3} \mathrm{~A}$ aplicação estrita dos modelos socialistas anteriormente comentados mostrou-se completamente inviá-

\footnotetext{
${ }^{2}$ As referências a Bilimovic e Krelle aparecem em Keizer (1989).

${ }^{3}$ Leonid V. Kantorovich é um economista matemático russo que usou a técnica de programação linear para aprimorar a teoria da alocação ótima dos recursos em seu livro O Melhor Uso dos Recursos Econômicos. Por sua contribuição, foi laureado com o premio Nobel de economia em 1975 (junto com T. Koopmans).
} 
vel. Eminentes planejadores das economias socialistas como Zielinsk (1969) e M. Augustinovics (1975) tão cedo se deram conta deste fato.

Com tudo o que foi dito, torna-se evidente que os modelos socialistas puros não descrevem um sistema econômico real. O mesmo também se pode dizer de modelos abstratos do funcionamento de uma economia de mercado. O modelo neoclássico de Leon Walras e de outros, mas também muito da descrição dessa economia pelos adeptos fervorosos de livre-mercado, não descrevem, de fato, economias capitalistas reais. É inegável que a contraposição de modelos puros é útil em muitos aspectos. O ponto em questão, todavia, é exatamente esse: o estudo dos modelos teóricos puros é mais do interesse de outras disciplinas da Economia do que da disciplina de SEC.

É inadequado para a disciplina SEC contrastar sistemas econômicos puros. $\mathrm{O}$ argumento principal na defesa desta tese é o de que comparações ideais não permitem auxiliar nas escolhas de políticas concretas. Não permitem, por exemplo, dizer em que momento seria interessante adotar soluções socialistas ou prómercado.

Até o inicio da década de 1990, muito freqüentemente cursos de SEC dedicavam-se a estudar a evolução e a transformação dos sistemas capitalistas e socialistas. No capitalismo, o respectivo tópico estudava a evolução histórica desse sistema econômico com base na descrição de autores como Dobb (1981) ou Galbraith (1983). Na seção de socialismo analisava-se a experiência da implantação do comunismo soviético, dentre outros casos concretos, no contexto das condições históricas e, em especial, da relação com o partido comunista burocrático e autoritário. Dentre os livros indicados, tradicionalmente liam-se Brus (1972 e 1973) e Zozlov (1977) e o mais recente Bottomore (1990).

Novamente, este parece ser um enfoque equivocado. A disciplina SEC não deve ser um estudo histórico, pois tal atitude levaria a uma invasão na seara dos historiadores. São eles que se dedicam a analisar o que se passou nas experiências históricas dos países com a implantação de novos sistemas econômicos.

O descrédito e a conseqüente supressão de SEC como disciplina na grade da graduação dos cursos de Economia, mesmo como matéria optativa, deve-se em grande parte a esse problema de focalização do seu objeto de estudo. A identificação do atual espectro político esquerda-direita na tabela 5 auxilia a construção da nova agenda para a disciplina SEC. Propõe-se que cada qual dos sistemas econômicos estudados venha associado à respectiva ideologia dentre as três remanescentes. O sistema econômico não fica totalmente caracterizado apenas pela identificação dos parâmetros econômicos que o condicionam. O substrato político-ideológico é essencial na definição da forma assumida pelo sistema econômico. Deve-se começar apontando em cada caso a ideologia que mais se aproxima da descrição do funcionamento de um sistema econômico concreto em nível de país.

Portanto, há um conjunto de sistemas econômicos associados à ideologia da social democracia do estado de bem-estar social, ao liberalismo de centro e ao neoliberalismo. A disciplina SEC deveria se ater a esses três conjuntos alternativos. Seu estudo consiste em identificar em cada caso concreto a existência de um 
tipo ideal (no sentido weberiano). Os tipos seriam então estudados não do ponto de vista histórico (evolução) nem do ponto de vista ideal, mas partindo-se da identificação de atributos gerais que permitam identificar todos os casos concretos e classificá-los nas alternativas. É evidentemente reconhecido que nem sempre se pode associar taxativamente um sistema econômico a uma das três ideologias. Pode-se pensar em uma continuidade de casos específicos com diferentes mentalidades, substratos ideológicos, graus de intervenção do Estado na economia etc.

A proposta apresentada pode ser fundamentada também empiricamente arrolando-se os países e, de uma maneira inicial e aproximada, procurando-se enquadrá-los em um dos tipos ideológicos apontados no espectro político. A parte suprimida do espectro político ainda corresponde a ideologias que podem oferecer princípios de organização e funcionamento a uma gama de sistemas econômicos em certos países. Demonstra-se, entretanto, que apenas uma minoria de países apresenta uma base de funcionamento econômico mantendo alguma relação com princípios extraídos de ideologias anacrônicas, como comunismo, fascismo e conservantismo monárquico, que inspiraram, no passado, sistemas econômicos hoje superados. A evidência empírica é contundente: poucos países hoje em dia organizam sua economia com base nesses princípios.

A tabela 6 resume a análise sobre "tipos de governo", levadas a efeito pelo estudo da Central de Inteligência dos EUA (CIA, The World Book), que abrange 233 países e protetorados. Por "tipo de governo" compreende-se não apenas sistemas políticos, mas uma descrição que contempla, em parte, aspectos do sistema econômico desses países, de modo que o estudo serve como aproximação para um levantamento dos sistemas econômicos da atualidade. Apenas cinco países são classificados de "comunistas" (2,1\% do universo de países): China, Cuba, Coréia do Norte, Laos e Vietnam. Mesmo entre eles, há pelo menos um caso em que a forma de governo comunista não corresponde a um sistema de planejamento centralizado e de eliminação do capital privado, como sabidamente o exemplo da China. Guarda alguma relação com os princípios ideológicos do conservantismo monárquico, apenas os casos com regimes políticos de monarquia constitucional (não parlamentar), poder eclesiástico, república islâmica, monarquia, sultanato e teocracia. Apenas 13,7\% dos países poderiam se enquadrar em sistemas econômicos guiados por princípios ideológicos do conservantismo monárquico. Apenas regimes políticos classificados de ditadura teriam alguma relação com a ideologia fascista: totalizam eles 4,3\% dos países. Assim sendo, em 79,8\% dos casos os regimes políticos dão indícios da presença de sistemas econômicos compatíveis com alguma forma de democracia e que poderiam ser perfeitamente tratados no espectro ideológico indo da esquerda social-democrática à direita neoliberal. Então há uma evidência empírica que aponta para a exeqüibilidade e alcance desta proposta de construção de um espectro político atualizado como base ideológica de sistemas econômicos correspondentes à boa parte dos casos observados. 
Tabela 6: Classificação dos sistemas econômicos com base

em informações sobre tipo de governo (233 países)

\begin{tabular}{|c|c|c|c|}
\hline Tipo de governo & $\begin{array}{c}\text { Sistema econômico } \\
\text { compatível }\end{array}$ & ro de países & Porcentagem \\
\hline $\begin{array}{l}\text { Commonwealth, } \\
\text { constitucional, } \\
\text { democracia } \\
\text { constitucional, } \\
\text { democracia, república } \\
\text { democrática, federativo, } \\
\text { república federal, } \\
\text { parlamentarismo } \\
\text { democrático, } \\
\text { parlamentarismo, } \\
\text { parlamentarismo } \\
\text { monárquico e república }\end{array}$ & Espectro político reduzido & 186 & 79,8 \\
\hline Comunismo & Comunismo e socialismo & 5 & 2,1 \\
\hline $\begin{array}{l}\text { Monarquia constitucional, } \\
\text { eclesiástico, república } \\
\text { islâmica, monarquia, } \\
\text { sultanato e teocracia }\end{array}$ & Conservantismo monárquico & 32 & 13,7 \\
\hline Ditadura & Fascismo & 10 & 4,3 \\
\hline
\end{tabular}

Fonte: The World Fact Book. https://www.cia.gov/cia/publications/factbook/docs/profileguide.html

Sobre a definição de cada um desses tipos de governo, ver https://www.cia.gov/cia/publications/factbook/docs/ notesanddefs.html\#2128

A reflexão teórica e empírica dos diversos casos concretos de sistemas econômicos atuais procuraria associar, em cada caso, o tipo de ideologia dentro do espectro político apresentado. Primeiramente, enquadra-se a ocorrência nas três faixas do espectro político. Casos dissonantes seriam categorizados como sistemas vinculados a ideologias caducas ou que tentam aproximar-se de um modelo puro de organização, pautado em experiências mal sucedidas do passado. Os casos atípicos seriam qualificados no mesmo rol tratando-se de identificar elementos comuns entre eles e o distanciamento da ortodoxia de seu tipo. O enquadramento ideológico dos tipos modernos consiste na identificação do substrato de idéias, visões, sentimentos e expectativas que legitimam o correspondente sistema. A partir de então, um passo seguinte e decisivo é identificar os modelos de funcionamento dos sistemas econômicos, ou seja, o funcionamento prático dessas economias, procurando classificá-las (mantidos os contornos ideológicos) dentro de modelos baseados em situações reais. Muito deles se referem a países desenvolvidos, outros se aplicam a experiências de países em desenvolvimento. 


\section{A NOVA AGENDA DOS TEMAS DE SEC}

Na prática, a ideologia da nova esquerda é compatível com diferentes subsistemas econômicos atuais que podem ser enquadrados em três modelos básicos:

1. A social-democracia européia é a que mais se aproxima do ideal de um estado de bem-estar social. Países como Holanda e Suécia cobram altos impostos dos seus cidadãos e oferecem, em troca, bons programas sociais extensivos à quase totalidade do público qualificado.

2. Também se poderiam enquadrar na modalidade de esquerda social-democrata países que fizeram parte, no passado, do chamado socialismo real (as ex-comunistas Europa Oriental e Rússia) ou que introduziram o livre-mercado e a propriedade privada, mantendo o regime (a China comunista). Isto porque são países que romperam com o dogma da propriedade coletiva dos meios de produção e passaram a estimular a concorrência de livre mercado e a propriedade privada. Mantiveram um Estado ainda grande, porém remodelado; combateram a antiga estrutura de empresas públicas e ampla coletivização e iniciaram a transição para o capitalismo, mantendo, no entanto, características peculiares herdadas da desmontagem do antigo sistema.

3. Países de economias capitalistas em desenvolvimento que apresentam amplos programas de ação social de relativo alcance, mas que mobilizam recursos bastante insuficientes em face das enormes carências da população, por falta de fundos ou por deficiências no desenho das estruturas dos programas sociais (o Brasil é um bom exemplo).

A disciplina de SEC deveria, em uma seção do programa, descrever os atributos gerais do sistema econômico social-democrata a que se poderiam enquadrar todos os três subsistemas anteriormente discriminados: governo grande, elevada carga tributária, participação direta do Estado na produção de bens, regime misto de propriedade etc. Em seguida, na mesma seção, seriam tratados os subsistemas que descrevem casos concretos. A literatura sobre a social democracia européia é conhecida; em destaque as referências dos trabalhos de Desmond King (1988), H. Milner (1990) e G. Myrdal (1960). O caso do subsistema econômico de centro-esquerda que substituiu o comunismo da Rússia e Europa Oriental é tratado, por exemplo, em Szentes (1990), Aganbegyan (1989) e Brus e Laski (1989), e as transformações da China são estudadas em Miliband, Panitch e Saville (1988) e Neuberger e Duffy (1976). O sistema social-democrata em países em desenvolvimento pode ser estudado apoiando-se na ampla literatura que trata da economia e dos programas sociais desses países. Por exemplo, Brasil, África do Sul, Índia e Indonésia seriam representativos como estudos de caso deste subsistema econômico.

O sistema econômico de centro seria o liberalismo não radical que defende um governo pequeno, mas que vê com bons olhos a intervenção do estado em 
ações pontuais sempre que a solução de mercado reconhecidamente não seja exeqüível ou não conduza ao ótimo social desejado. Os casos concretos deste sistema econômico liberal cobrem uma gama de países, em geral desenvolvidos. A história comum deles é o fato de não terem atravessado no passado a experiência do socialismo. Anteriormente tiveram uma presença mais forte do Estado, alguns chegaram a implantar um sistema social-democrata com Estado grande na promoção do bem-estar social, mas migraram deste sistema, desmontaram significativamente as estruturas desse Estado e reduziram programas sociais, o que, portanto, resultou na adoção de um sistema de centro. Não obstante, o Estado ainda faz-se presente, controlando e interferindo em alguns aspectos no funcionamento da economia. A presença do Estado, nesses casos, é menor que nas sociais democracias de esquerda. Os EUA, e mesmo países menos desenvolvidos como o Chile, exemplificam sistemas econômicos de centro. A literatura que fala das reformas recentes nessas economias e da nova dimensão do Estado nelas seria então abordada nesta parte do programa da disciplina.

O sistema econômico neoliberal, muito embora esteja associado a modelos puros de economias de Estado mínimo, pode perfeitamente ser empregado como descrição básica de economias atuais em que o Estado intervem muito pouco; menos do que nos casos de centro citados anteriormente. Alguns países do extremo oriente apresentam, hoje em dia, características essencialmente neoliberais no funcionamento de suas economias. Japão, Taiwan e Singapura, por exemplo, são exemplos de países que, por suas características, contemplariam a direita neoliberal do espectro dos sistemas econômicos. Pequenos programas de ação social, de alcance limitado, impostos relativamente baixos, leis bastante favoráveis à livre iniciativa e outras características econômicas, classificam esses casos no tipo ideal em questão.

Tabela 7: Modernos sistemas econômicos identificados para o estudo de SEC

\begin{tabular}{lll}
\hline Ideologia política & \multicolumn{1}{c}{ Sistema econômico } & \multicolumn{1}{c}{ Exemplo de países } \\
\hline $\begin{array}{l}\text { Social democracia do estado } \\
\text { de bem-estar social }\end{array}$ & Estado de bem-estar social europeu & $\begin{array}{l}\text { França, Alemanha, } \\
\text { Holanda, Suécia, Itália } \\
\text { Irlanda, Reino Unido }\end{array}$ \\
\hline \multirow{2}{*}{\begin{tabular}{ll} 
Liberalismo \\
\cline { 2 - 3 }
\end{tabular}} & Países em desenvolvimento & Rússia, Polônia, China \\
\hline Neoliberalismo & Outros & Brasil, Índia, Indonésia \\
\hline & Modelo japonês & Canadá Austrália \\
\hline
\end{tabular}

A tabela 7 sintetiza a classificação dos sistemas econômicos, situando-os em termos de ideologia política e, ainda, exemplificando países. Cada sistema econômico deve ser estudado identificando-se modelos baseados em situações reais. 
Por exemplo, o sistema de bem-estar social remete aos modelos europeus (renano, franco-germano, escandinavo, anglo-saxão e mediterrâneo), ${ }^{4}$ ou aos modelos associados à experiência de países que migraram de um sistema econômico comunista para as economias de mercado, ou os diversos casos para os países em desenvolvimento. O sistema econômico liberal associa-se ao modelo americano e a outros modelos liberais como no Canadá e na Austrália. Para o sistema neoliberal, tem-se o caso do Japão e os modelos encontrados em países como Taiwan e Singapura.

\section{CONSIDERAÇÕES FINAIS}

Esta classificação não é absoluta, mas permite apreender a maioria dos casos. Cada um desses modelos concretos de sistemas econômicos deve ser descrito em seus atributos principais. Em seguida, uma análise do funcionamento de cada qual ofereceria uma base para diferentes parâmetros de comparações entre eles. Pode-se concluir, por exemplo, que o sistema do estado de bem-estar social europeu tende a combinar níveis elevados de proteção ao emprego com alta cobertura de seguro desemprego, enquanto o modelo americano pratica uma política trabalhista completamente diferente. Dados estes aspectos dos respectivos sistemas econômicos, a nova disciplina de SEC poderia examinar qual dos diferentes modelos funciona melhor na consecução dos objetivos de estimular elevados níveis de emprego com eliminação da pobreza relativa. Com relação a um desses critérios um sistema econômico pode funcionar melhor, mas estar, ao mesmo tempo, em desvantagem relativamente a outro critério.

A comparação entre sistemas econômicos deve ainda ter um caráter normativo: concluir-se-ia desses estudos que um sistema aparentemente bem-sucedido pode ser implementado por outros países. No entanto, a viabilidade de adoção de um sistema econômico por outro grupo de países requer não apenas uma mu-

\footnotetext{
${ }^{4}$ Há pelo menos quatro maneiras distintas de implementação do Estado de Bem-Estar Social na Europa: O "modelo escandinavo" (Dinamarca, Finlândia, Suécia e Holanda) tem os mais elevados gastos públicos aplicados em proteção social e provisão de bem-estar universal. Os mercados de trabalho são pouco regulamentados, mas existem políticas ativas visando o mercado de trabalho, enquanto sindicatos fortes proporcionam um grau elevado de igualdade salarial. O modelo anglo-saxão (Reino Unido e Irlanda) proporciona uma assistência social de última instância bastante generosa, com transferências de dinheiro destinadas principalmente a pessoas em idade economicamente ativa. Os sindicatos são frágeis e o mercado de trabalho é relativamente pouco regulamentado. O modelo renano (Áustria, Bélgica, França, Alemanha e Luxemburgo) baseia-se em seguro social para os desempregados e na provisão de aposentadorias. A proteção ao emprego é mais forte do que nos países nórdicos. Os sindicatos também são poderosos ou desfrutam de apoio legal para a extensão de resultados de negociação coletiva. Finalmente, o modelo mediterrâneo (Grécia, Itália, Portugal e Espanha) concentra gastos públicos no pagamento de aposentadorias de idosos. Forte regulamentação protege o trabalhador, aumentando o desemprego, ao passo que generoso apoio a aposentadorias antecipadas reduz o número de pessoas em busca de trabalho.
} 
dança de valores e de mentalidade (prioridade do êxito pessoal ou comprometimento com níveis elevados de bem-estar social?), mas a capacitação de sua população (alto nível de escolaridade). Até que ponto um sistema apoiado por um conjunto de crenças mais liberais poderia tolerar um sistema em que os níveis dos gastos públicos em relação ao PIB ultrapassam os $50 \%$ ? O modelo pode funcionar bem para um grupo de países, mas ter uma aplicabilidade discutível para outros países.

Países com desigualdade de renda e com população mais heterogênea tendem a adotar um sistema econômico diferente de países mais ricos e homogêneos. No caso do Brasil, é evidente a necessidade de um sistema econômico que destine parte significativa das despesas do Estado com gastos sociais.

Então há diversas questões interessantes que poderiam ser estudas pela disciplina de SEC. Na sua nova ementa, não se trata mais de comparar sistemas econômicos puros e estilizados, trata-se, outrossim, de apontar as semelhanças e dessemelhanças no funcionamento de casos concretos e apontar a possibilidade de replicar experiências bem-sucedidas. Evidentemente o estudo de casos concretos requer o aporte de uma análise teórica de Sistemas econômicos comparados, que remeta a princípios ideológico e modos de funcionamento.

\section{REFERÊNCIAS BIBLIOGRÁFICAS}

Aganbegyan, Abel (1989) Inside Perestroika: The Future of the Soviet Economy. Nova York: Harper \& How.

Augustinovics, Maria (1975) "Integration of mathematical and traditional methods of planning". In: Bornstein, Morris (ed.) Economic Planning: East and West, Cambridge, MA: Ballinger.

Barone, Enrico ([1908] [1935] 1975) "The ministry of production in the collectivist State”. In: Hayek, Friedrich A. (ed.) Collectivist Economic Planning. Clifton, NJ: Augustus M. Kelley.

Bergson, Abram (1948) "Socialist economics". In: Ellis, Howard S. (ed.) A Survey of Contemporary Economics. Philadelphia: The Blakistan Co..

Bottomore, Tom (1990) The Socialist Economy: Theory and Practice. Hertfordshire: Harvester Wheatsheaf.

Brus, Wlodzimierz (1972) The Market in a Socialist Economy. Londres: Routledge \& Kegan Paul. . (1973) The Economics and Politics of Socialism. Londres: Routledge \& Kegan Paul.

Brus, Wlodzimierz e Laski, Kazimierz (1989) From Marx to the Market. Oxford: Clarendon Press.

Chaloupek, Günther K. (1990) “The Austrian debate on economic calculation in a socialist economy". History of Political Economy 22(4): 659-675.

Dobb, Maurice (1981) A Evolução do Capitalismo. Rio de Janeiro: Zahar.

Galbraith, John K. (1983) O Novo Estado Industrial. São Paulo: Pioneira.

Kantorovich, Leonid V. (1965) The Best Use of Economic Resources. Oxford: Pergamon Press.

Keizer, Willem (1989) "Recent reinterpretations of the socialist calculation debate". Journal of Economic Studies 16(2): 63-83.

King, Desmond S. (1988) "O Estado e as estruturas sociais de bem-estar em democracias industriais avançadas”. Novos Estudos 22(outubro): 53-76.

Kozlov, G. (ed.) (1977) Economía Política: Socialismo. Moscou: Progreso.

Lange, Oskar R. (1936) "On the economic theory of socialism, part 1". The Review of Economic Studies, 4(1): 123-142.

Lerner, Abba P. (1944) The Economic of Control. Nova York: Macmillan. 
Lindblom, Charles. E. (1977) Politics and Markets. Nova York: Basic Books.

Miliband, Ralph, Panitch, L eo e Saville, John (1988) Socialist Register 1988: Problems of Socialist Renewal. East and West. Londres: The Merlin Press.

Milner, Henry (1990) Sweden: Social Democracy in Practice. Oxford: Oxford University Press.

Myrdal, Gunnar (1960) Beyond the Welfare State. New Haven: Yale University Press.

Neuberger, Egon e Duffy, William (1976) Comparative Economic Systems: A Decision Making Approach. Boston: Allyn \& Bacon.

Pryor, Frederic L. (1985) A Guidebook to the Comparative Study of Economic Systems. Nova Jersey: Prentice-Hall.

Stackelberg, Roderick (2003) A Alemanha de Hitler: Origens, Interpretações,Legados. São Paulo: Imago.

Szentes, Tamás (1990) "La transición desde las 'economías de planificación centralizada' a las 'economías de mercado' en la Europa del Este y la URSS: la ruptura con el stalinismo". In: Pensamiento Iberoamericano 18: 125-144.

Vickers, John e Arrow, George (1989) Privatization: An Economic Analysis. Cambridge: The MIT Press.

Zassenhaus, Herbert (1956) "On the theory of economic planning”. International Economic Papers 25(1).

Zielinski, Janusz G. (1969) "Economics and politics of economic reforms in Eastern Europe". Economics and Planning 9(3): 279-295.

Zimbalist, Andrew e Sherman, Howard J. (1984) Comparing Economic Systems: a political-economic approach. Orlando: Academic Press. 